\title{
Using MODIS for mapping flood events for use in hydrological and hydrodynamic models: Experiences so far
}

\author{
C.J. Ticehurst $^{\text {a }}$, Y. Chen ${ }^{\text {a }}$, F. Karim ${ }^{\text {a }}$, D. Dutta ${ }^{\text {a }}$, B. Gouweleeuw ${ }^{\text {a }}$ \\ ${ }^{a}$ CSIRO Land and Water, Black Mountain, Canberra \\ Email: catherine.ticehurst@csiro.au
}

\begin{abstract}
Daily, or more frequent, maps of surface water have important applications in environmental and water resource management. In particular, surface water maps derived from remote sensing imagery play a useful role in the derivation of spatial inundation patterns over time and in calibrating and validating hydrological and hydrodynamic models. While MODIS data provide the most realistic means to achieve this, they are often limited by cloud cover during flooding events, and their spatial resolutions $(250-1000 \mathrm{~m}$ pixel) are not always suited to small river catchments. This paper tests the suitability of MODIS for providing daily surface water maps, both spatially and temporally, across a range of Australian catchments. This study shows that MODIS is suitable for capturing both medium and large flood events, but lacks the detail around the edge of a flood or along narrow water features where it tends to underestimate water extent. Compared to a Landsat water map, the MODIS water maps have shown a strong-to-moderate statistical agreement. Soils are sometimes mapped as wet when they are not, possibly due to confusion with moisture in the soil and/or soil colour. Flooding under dense vegetation is often invisible to MODIS or any other optical remote sensor. Care must also be taken when using MODIS data along the edge of the image swath where the water extent can be underestimated. The view angle, or range distance from sensor to pixel, influences the amount of water that can be mapped, as is demonstrated with a permanent water body. On a temporal scale, cloud cover often inhibits the use of MODIS imagery at the start and lead-up to the peak of a flood event, but there are usually more cloud-free data to monitor the flood's recession. MODIS surface water maps are sensitive to the dynamics of water movement when compared to flow gauge data. Given their temporal and spatial characteristics, the MODIS sensors can provide useful information for hydrodynamic modelling, and do appear to be the best available product for mapping inundation extent and its change dynamics at large regional/basin scales.
\end{abstract}

Keywords: Optical remote sensing, surface water mapping, flood inundation 


\section{INTRODUCTION}

Regular mapping of surface water location and extent, often at a daily or more frequent temporal scale, has important applications in environmental monitoring, water resource management, and flood emergency response. Contemporary remote sensing technologies provide an affordable means of capturing flood extent at points in time with reasonable spatial and temporal coverage, which can be integrated with hydrological and hydrodynamic models to develop a complete record of flood response through time. For flood monitoring there is a need for routinely acquiring freely available remote sensing data which have regional coverage at an acceptable spatial resolution. Landsat imagery can provide the appropriate spatial detail for hydrological modelling, but its temporal frequency of 16 days is not suited to capturing many flood events. Recent work using LiDAR DEM has shown it to be suitable for floodplain inundation modelling (Teng et al., 2013), when the data are available. Optical systems such as AVHRR and MODIS have been used for mapping surface water at a medium spatial resolution. While the resolution of the MODIS sensor may not be ideal for mapping small water features such as narrow river channels, the spatial and temporal consistency can still be of great value in detecting general change in water movement.

Optical data, particularly MODIS, can be used for mapping flood events due to its near-global spatial $(250 \mathrm{~m}$ $-1 \mathrm{~km}$ ) and temporal scale (1-2 times/day). Furthermore, all historical data from 2000 to the present are readily available. MODIS bands 1 (Red) and 2 (NIR) are at $250 \mathrm{~m}$ pixel size and have been used to capture large global flood events through the Dartmouth Flood Observatory (http://floodobservatory.colorado.edu/ ) (Brakenridge and Anderson 2006), as well as environmental monitoring of seasonal flood patterns on floodplains (Ward et al., 2012). Water fraction of a MODIS pixel has also been used at a larger pixel size to make use of the longer SWIR (Short Wave InfraRed) bands (6 and 7) which are related to open water (Xu, 2006). Guerschmann et al. (2011) uses a detailed empirical approach with the MODIS bands, utilizing the strong relationship between NDVI, NDWI, the SWIR bands and surface water, producing fractional water coverage at 500m pixel size. Weiss and Crabtree (2011) use NDVI, NDWI and tasselled cap to derive water fraction at $1 \mathrm{~km}$ pixel.

Cloud cover is always an issue when trying to map flood events using optical remote sensing, especially during the rising stage of a flood event. To help reduce the effects of cloud interference, the use of 8-day (MOD09A1) or 16-day (MCD43A4) MODIS composites (provided by NASA) has proven useful in mapping the temporal dynamics of water (Ordoyne and Friedl 2008; Chen et al., 2011; Weiss and Crabtree 2011; Chen et al., 2012; Huang et al., 2012a; Huang et al., 2012b; Chen et al., 2013). However some of the temporal detail may be lost through the compositing process (Guerschmann et al., 2011), which makes MODIS composites inadequate for fast moving floods.

Daily MODIS water maps have already been used to assist in the calibration of hydrodynamic models at different stages of a flood event (Karim et al., 2011). This paper investigates in more detail the suitability and limitations of using daily MODIS data to map flood events for use in hydrodynamic models. In particular, it focuses on the spatial and temporal reliability of daily MODIS flood maps for flood events, using case studies from three regions of different environmental and flood characteristics, as well as the influence of view angle on flood extent. The abilities and challenges of using optical remote sensing, in particular MODIS, to map flood extent for use in hydrodynamic models are then discussed.

\section{THE STUDY SITES}

Three study sites were selected for testing the ability of using MODIS to map a flood event. The CondamineBalonne flood plain was selected as one local test site due to its recent large flood events. The Fitzroy River floodplain was chosen due to its relatively small flood extent on undulating topography which often results in a well-contained flood event. In contrast, the Macquarie Marshes was also selected as it is a wetland in relatively flat topography consisting of many small, vegetated water channels.

The Condamine-Balonne catchment is situated in southeast Queensland, Australia (Figure 2a). The area of interest is to the south of the township of St George down to the Queensland border (referred to as the lower Balonne floodplain), where flooding mostly occurs due to upstream rainfall events. Water in this area is heavily regulated, with water extracted from the river and stored in ring tanks for irrigation purposes when there are sufficient flows. This is a semi-arid environment where flood events occur on a relatively short time-frame, usually days to weeks, with the floodplain covering approximately $3,800 \mathrm{~km}^{2}$. This area consists of open woodland on alluvial plains, where the soil is mainly cracking clay soils as well as duplex soils (Apan and Sternes, 2006). 
The Fitzroy catchment is located in northwest Australia in the state of Western Australia (Figure 2b). This tropical catchment covers almost $94,000 \mathrm{~km}^{2}$, with the alluvial sediments covering more than $32,000 \mathrm{~km}^{2}$. During the wet season, the Fitzroy River can grow in size up to $15 \mathrm{~km}$ across the alluvial floodplain. The vegetation in this floodplain consists of acacia shrublands, open woodlands, and grasslands (CSIRO 2009).

The Macquarie Marshes, located in the central north of New South Wales, Australia (Figure 2c), are an extensive, semi-permanent inland wetland system which has a network of interconnecting channels, lagoons, effluents and associated overflow areas. The wetlands are characterised by the layer of fresh water essentially fed by rainfall and the Macquarie River (Macaulay and Kellett, 2009). The area of the wetlands depends on water availability and extends to about $3,000 \mathrm{~km}^{2}$ during major floods (Thomas et al., 2011).

\section{METHOD}

The TERRA and AQUA MODIS surface reflectance data (named MOD09GA and MYD09GA, respectively) were downloaded from the NASA LP DAAC (Land Processes Distributed Active Archive Centre) website: http://reverb.echo.nasa.gov/reverb . The method used for mapping open surface water was developed by Guerschmann et al., (2011) using empirical statistical modelling and is summarized here. It calculates the fraction of water within a MODIS pixel by:

$$
\begin{array}{cl}
f_{w}=\frac{1}{1+\exp (z)} \quad(1) \text { where } z \text { is defined as } & \multicolumn{1}{l}{\begin{array}{l}
5=\beta_{0}+\sum_{i=0}^{5} \beta_{i} \cdot x_{i} \quad(2) \text { and } \\
\beta 0=-3.41375620
\end{array}} \\
\beta 1=-0.000959735270 & x 1=\text { SWIR band 6 (reflectance*1000) } \\
\beta 2=0.00417955330 & x 2=\text { SWIR band 7 (reflectance*1000) } \\
\beta 3=14.1927990 & x 3=\text { NDVI } \\
\beta 4=-0.430407140 & x 4=\text { NDWI (Gao, 1996) } \\
\beta 5=-0.0961932990 & x 5=\text { MrVBF index (Gallant and Dowling, 2003) }
\end{array}
$$

SWIR is Short Wave Infrared, NDVI is the Normalized Difference Vegetation Index, NDWI is the Normalized Difference Water Index, and MrVBF is the Multi-resolution Valley Bottom Flatness index. A threshold is applied using the modified NDWI (Xu, 2006) where $f_{w}=1$ for all $m N D W I>0.8$ (Guerschmann et al., 2011).

A cloud mask is also applied using the accompanying MODIS state band which contains information on cloud and cloud-shadow location. As MODIS data are available twice daily (one from AQUA and one from TERRA), any overlapping data were combined such that nulls or cloud pixels are replaced by the other image (where available) when producing daily temporal data. For pixels containing fractional water $\left(f_{w}\right)$ from both the AQUA and TERRA images, the pixel associated with the smallest view angle is used.

Higher spatial resolution Landsat data were used as "ground truth" for assessing how well the MODIS products could map flood extent in the lower Balonne floodplain, Fitzroy River and Macquarie Marshes during a flood event. All images for each region were selected such that they had as similar acquisition time as the MODIS images as possible (Table 1). Using the Landsat data, a water map was produced for these scenes using the Modified NDWI with a threshold greater than zero being masked as water (using Green band 2 and SWIR band $5-\mathrm{Xu}, 2006)$. The MODIS scenes were then georeferenced to the Landsat scenes as accurately as possible. The MODIS water percentage maps need to be converted to water/non-water maps for use in hydrodynamic modelling, which required a threshold to be selected from the water percentage map. This was done by calculating how well the MODIS water map compared to the Landsat water map for each MODIS water threshold for each study site. The accuracy (using Landsat as "ground truth") was based on the Kappa statistic (Landis and Koch, 1977), rather than overall percentage of MODIS pixels agreeing with Landsat, due to the large number of non-water pixels in the images.

Table 1. Dates and UTC times (in brackets) of the Landsat and MODIS images for the three study sites.

\begin{tabular}{|l|l|l|}
\hline & Landsat & MODIS \\
\hline Lower Balonne & $21 / 01 / 2011(23.50)$ & $21 / 01 / 2011(0.20)$ \\
\hline Fitzroy & $8 / 04 / 2007(1.37)$ & $8 / 04 / 2007(5.35)$ \\
\hline Macquarie Marshes & $20 / 12 / 2010(23.51)$ & $21 / 12 / 2010(5.13)$ \\
\hline
\end{tabular}


Stream flow data from gauges at Fitzroy Crossing (802055) and Looma (802007) (from the Department of Water, Government of Western Australia) for a flood event in the Fitzroy River (WA) for early April 2007, and Bells Bridge (421012) and Gin Gin (421031) (from Office of Water, State of New South Wales) for Macquarie Marshes in December 2010 - February 2011, were plotted along with the total MODIS water extent for the floodplains. This was to test the ability and sensitivity of the sensor to detect change in water extent through time and indirectly compare it to in situ data. Flow data were taken from two measuring stations, one at the upstream section, and the other at the lower end, with respect to the area used to measure water extent in the imagery. The lower Balonne was not included in this analysis since it is a heavily regulated system consisting of large ring tanks with steep soil banks. Hence an increase in in-flow into the floodplain would not necessarily result in an increase in visible flood extent.

An example of the influence of view angle, expressed through the range distance from sensor to pixel, is also given for a permanent Lake, in this case Lake Victoria on the Chowilla floodplain in New South Wales, Australia. The change in number of fully flooded pixels within the lake (i.e. measuring as $100 \%$ water) is shown over a 6 day period and compared to the range distance.

\section{RESULTS}

\subsection{Spatial Comparison with Landsat}

For the three study sites, a threshold was iteratively applied to the MODIS water $f_{w}$ (converted to percentage maps) from 1 to $100 \%$, such that any pixel containing water at or above the threshold was mapped as water. This was compared to the Landsat water maps for the lower Balonne, Fitzroy and Macquarie Marshes study sites and the accuracy was calculated based on the Kappa statistic (Figure 1). The results show that the best match of MODIS with Landsat occurs with a water percentage threshold of $6 \%, 3 \%$ and $3 \%$ for the lower Balonne, Fitzroy and Macquarie Marshes respectively. Their respective Kappa statistics are 0.8 (strong agreement), 0.62 (substantial agreement) and 0.55 (moderate agreement) (Landis and Koch 1977; Jensen 2005). The spatial difference between the MODIS and Landsat image pairs using the highest accuracy water percentage threshold is shown in Figure 2 for each study site.

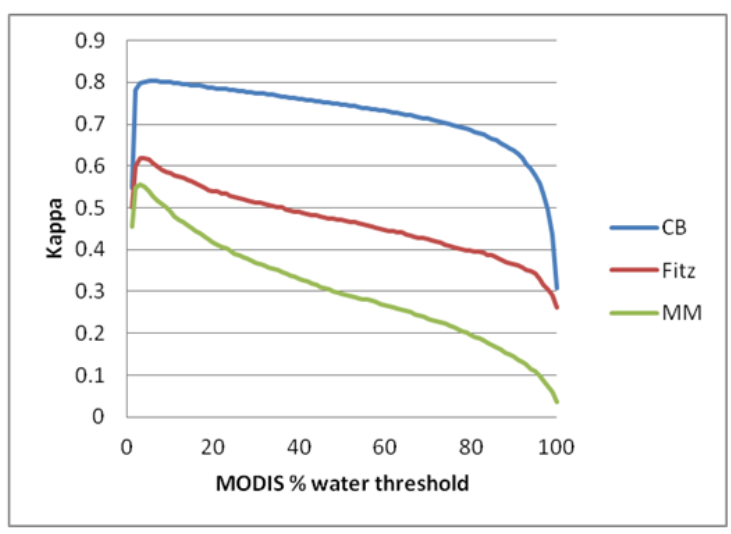

Figure 1. Comparison of Landsat and MODIS water maps for Lower Balonne floodplain (CB), Fitzroy River (Fitz) and Macquarie Marshes (MM) for the different MODIS water percentage thresholds based on the Kappa statistic.

Figure 2 illustrates how the MODIS and Landsat water maps tend to agree (in blue) where there are large, open bodies of water. Narrow river channels are not mapped in the MODIS, compared to the Landsat (orange). The Macquarie Marshes are also showing a substantial area that is mapped as water in the MODIS but not the Landsat (green). Inspection of the Landsat reflectance image shows these areas have little to no vegetation cover, hence the soil is influencing the water percentage value possibly due to moisture within the soil or soil colour. In Figure 2a, large patches of orange are indicating where the Landsat is mapping water and the MODIS is not. This is probably due to the time difference between the two acquisitions and the progression of the flood during this time. Figure 2a also shows patches that are not flooded in the centre of the lower Balonne floodplain. These areas are cotton crops which are heavily vegetated and very green. It is most likely that they have underlying water due to irrigation, however this is not detected in either the MODIS or Landsat water maps. 

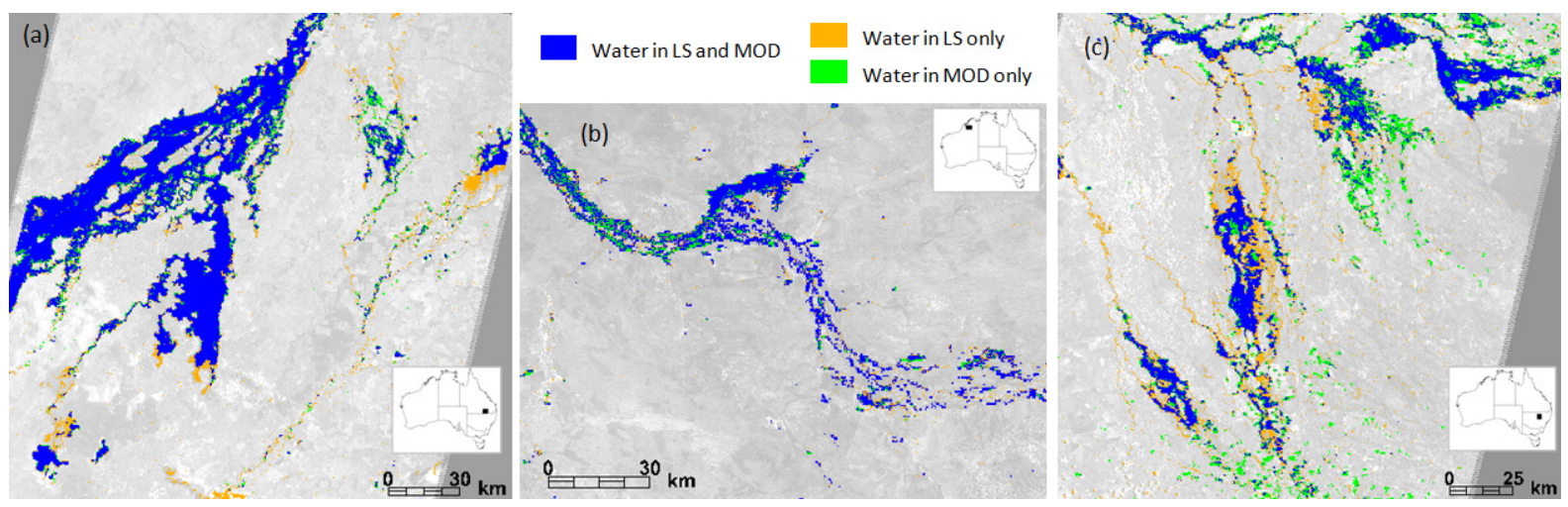

Figure 2. Comparison of Landsat (LS) and MODIS (MOD) water maps for lower Balonne floodplain (a), Fitzroy River (b) and Macquarie Marshes (c). The site locations within Australia are shown in inserts.

\subsection{Temporal Comparison with Flow Gauge data}

When the total flood extent from the MODIS images is indirectly compared to gauged inflow and outflow data for the Fitzroy River (Figure 3), it can be seen that MODIS is detecting the flood event. Water flow through this section of river has no significant anthropogenic influences that are likely to change the input or output flows. The in situ measurements of upstream and downstream discharge (in $\mathrm{m}^{3} / \mathrm{sec}$ ) show that the peak of the flood as derived from the temporal MODIS flood extents fall between the measured inflow and outflow peaks as expected. While the measured discharge is not directly comparable to the area of the water surface, they both provide an indication of flood event magnitude and duration. Similar results are seen for the Macquarie Marshes floodplain (Figure 4). MODIS is able to show the peak and end of the flood event, when indirectly compared to the upstream and downstream flood gauges. What is very apparent in both of these examples is the lack of MODIS flood extent images during the early stages of the flood. This is due to constant cloud cover, making it impossible to obtain optical remote sensing imagery.

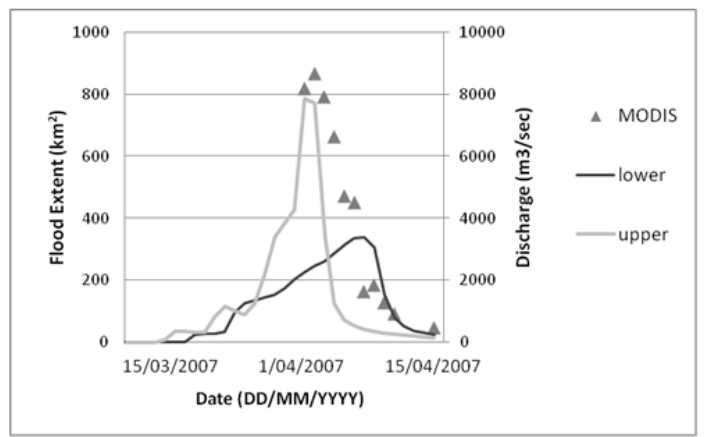

Figure 3. Flood extent as derived from MODIS for the 2007 flood in the Fitzroy River area, along with observed discharge $\left(\mathrm{m}^{3} / \mathrm{sec}\right)$ from upstream (Upper - 802055) and downstream (Lower - 802007) of the area of interest.

\subsection{Other influences on MODIS water map quality}

The sensor view angle, expressed here through the MODIS Range Distance from sensor to pixel, does influence the image, and hence MODIS water map quality. It has greatest influence on the edge of the MODIS swath, where the view angle, and hence range distance, is greatest. Figure 5 shows an example of this effect. Lake Victoria is a permanent lake in New South Wales. A MODIS water map has been created for this lake for different range distances. The longest range distance (most right image) shows the least number of fully flooded pixels $(100 \%)$ in Cyan, even

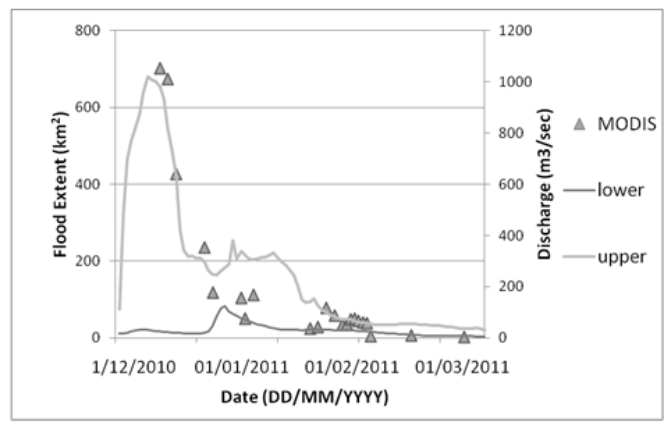

Figure 4. Flood extent as derived from MODIS for the 2010/2011 flood in the Macquarie Marshes area, along with observed discharge $\left(\mathrm{m}^{3} / \mathrm{sec}\right)$ from upstream (Upper - 421031) and downstream

(Lower - 421012) of the area of interest.

though the date of this image was one day after the left hand image, and one day before the second image from the left. Figure 5 also graphs the strong relationship between range distance and number of fully flooded pixels in Lake Victoria. These images are within six days of each other so most of the changes observed in water extent appear to be related to the view angle. 

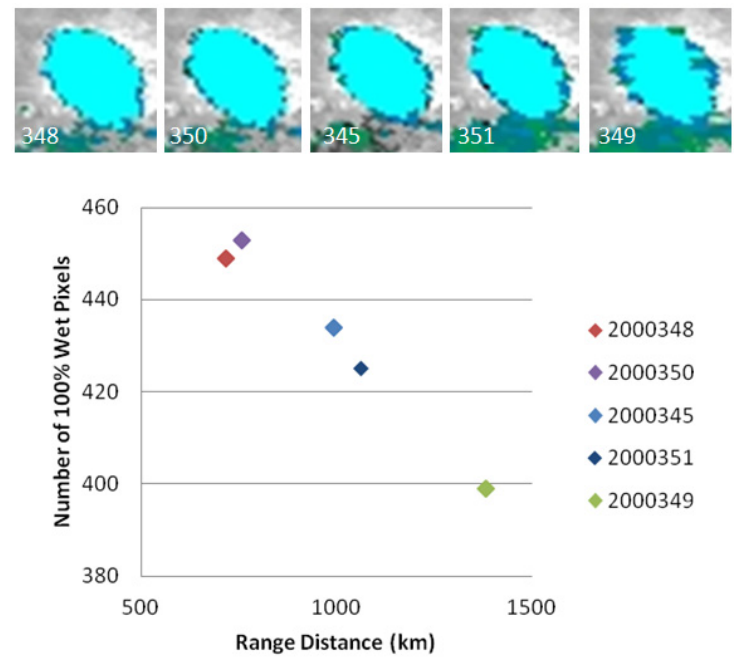

\section{DISCUSSION AND CONCLUSIONS}

Water maps generated from remote sensing imagery are particularly useful for covering large areas at a reasonable temporal frequency. While MODIS is able to provide daily water maps, it is of a coarser spatial resolution ( $250 \mathrm{~m}-1 \mathrm{~km}$ pixel size) compared to Landsat (30m pixels). The suitability of MODIS for use in flood analysis is very much dependent on the user's requirements. The MODIS maps of surface water are not of sufficient detail to map narrow water features of less than 1 pixel in width. This problem is even more exaggerated when the narrow river channel is covered by vegetation, which obscures the water from the sensor. The best results from the MODIS water maps tend to be in the lower catchments during large flood events.

Even though the MODIS sensors were imaging at a sub-daily interval, cloud cover is still a major problem when mapping flood events, particularly before the flood peak. Most of the cloud-free images were available during the floods recession. To help overcome this limitation, it might be possible to use historical MODIS water maps to help fill in the gaps for a characteristic flood event. Historical summary maps of maximum extent, and number of days that a pixel is under water, might also be useful when correlated to flow gauge records of flood size. This type of information could be integrated into hydrodynamic models to help define flood progression for characteristic flood events (rather than extreme - record breaking ones).

Care must be taken when interpreting the MODIS water maps due to confusion with bare soils (possibly due to moisture in the soil and soil colour), and fluctuations in flood extent due to view angle. A flood-likelihood mask would benefit interpretation of the data, eliminating areas where flooding is impossible. A small view angle (or range distance) is ideal for providing the best image quality. However this would reduce the number of useable images for a flood event. For priority areas it might be possible to use a series of historical MODIS water maps, and develop a relationship between view angle and water extent, correcting for those areas with a large view angle.

When cloud-free data are available, MODIS is able to show a large flood's progression through time. Despite its limitations, MODIS is still useful for providing flood extent maps during a flood event, which can be used for the calibration and adjustment of hydrodynamic models.

\section{ACKNOWLEDGEMENTS}

This work has been part of the CSIRO Water for a Healthy Country and the CSIRO Sustainable Agriculture Flagships.

\section{REFERENCES}

Apan,A., and Sternes, P. (2006). Mapping and spatio-temporal analysis of flooded and inundated areas in the Lower Balonne Floodplain, Queensland, Australia. WSEAS Transaction on Environment and Development, $4(2), 360-367$

Brakenridge, R., and Anderson, E. (2006). MODIS-based flood detection, mapping and measurement: The potential for operational hydrological Applications. Transboundary Floods: Reducing the Risks through Flood Management, 72, 1-12. 
Chen, Y., Cuddy, S.M., Wang, B., Merrin, L.E., Pollock, D., and Sims, N. (2011) Linking inundation timing and extent to ecological response models using the Murray-Darling Basin Floodplain Inundation Model (MDBFIM). In: Chan F, Marinova D, Anderssen RS (eds) Proceedings of MODSIM2011: The 19th International Congress on Modelling and Simulation: 4092-4098.

Chen, Y., Wang, W., Cuddy, S., Pollino, C., and Merrin, L.E. (2012). Spatial modelling of potential water retention under floodplain inundation using remote sensing and GIS. In: Proceedings of iEMSs 2012: The 6th International Congress on Environmental Modelling and Software Modelling, Leipzig, Germany.

Chen, Y., Huang, C., Ticehurst, C., Merrin, L. and Thew, P. (2013). An evaluation of MODIS daily and 8-day composite products for floodplain and wetland inundation mapping. Wetlands. DOI 10.1007/s13157-0130439-4.

CSIRO (2009). Water in the Fitzroy region, pp 61-128 in CSIRO (2009) Water in the Timor Sea Drainage Division. A report to the Australian Government from the CSIRO Northern Australia Sustainable Yields Project. CSIRO Water for a Healthy Country Flagship, Australia. 508pp.

Gallant, J.C., and Dowling, T.I. (2003). A multiresolution index of valley bottom flatness for mapping depositional areas. Water Resources Research, 39, 1347.

Gao, B-C. (1996). NDWI - A Normalized Difference Water Index for remote sensing of vegetation liquid water from space. Remote Sensing of Environment, 58, 257-266.

Guerschman, J.P., Warren, G., Byrne, G., Lymburner, L., Mueller, N., and Van-Dijk, A. (2011). 'MODIS-based standing water detection for flood and large reservoir mapping: algorithm development and applications for the Australian continent. Water for a Healthy Country National Research Flagship Report ', Canberra.

Huang, C., Chen, Y., Wu, J., and Yu, J. (2012a). Detecting floodplain inundation frequency using MODIS timeseries imagery. In: Proceedings of Agro-Geoinformatics2012: The 1st International Conference on AgroGeoinformatics, Shanghai, China.

Huang, S., Li, J., and Xu, M. (2012b). Water surface variations monitoring and flood hazard analysis in Donting Lake area using long-term Terra/MODIS data time series. Natural Hazards, 62, 93-100.

Jensen, J.R. (2005). An introductory digital image processing: a remote sensing perspective. Prentice Hall, New Jersey, p 526.

Karim, F., Petheram, C., Marvanek, S., Ticehurst, C., Wallace, J. and Gouweleeuw, B. (2011). The use of hydrodynamic modelling and remote sensing to estimate floodplain inundation and flood discharge in a large tropical catchment, in Chan, F., Marinova, D. and Andersson, R.S. (Eds.), $19^{\text {th }}$ International Congress on Modelling and Simulation, Perth, December 12- December 16, 2011, pp.3796-3802.

Landis, J.R., and Koch, G.G. (1977). The measurement of observer agreement for categorical data. Biometrics, 33(1):159-174.

Macaulay, S., and Kellett, J. (2009). Mapping groundwater and salinity using airborne electromagnetics in the Lower Macquarie River Valley, New South Wales. Australian Government Bureau of Rural Sciences.

NASA Land Processes Distributed Active Archive Center (LP DAAC) (2001). MOD09GA and MYD09GA. USGS/Earth Resources Observation and Science (EROS) Center, Sioux Falls, South Dakota.

Ordoyne, C., and Friedl, M.A. (2008). Using MODIS data to characterize seasonal inundation patterns in the Florida Everglades. Remote Sensing of Environment, 112(11), 4107-4119.

Teng, J., Vase, J., and Dutta,D. (2013). Simplified methodology for floodplain inundation modelling using LiDAR DEM. In Proceedings of H01, IAHS-IAPSO-IASPEI Assembly, Gothenburg, Sweden, 22-26 July 2013.

Thomas, R.F., Kingsford, R.T., Lu, Y., and Hunter, S. (2011). Landsat mapping of annual inundation (19792006) of the Macquarie Marshes in semi-arid Australia. International Journal of Remote Sensing, 32, 45454569.

Ward, D.P., Hamilton, S.K., Jardine, T.D., Pettit, N.E., Tews, E.K., Olley, J.M., and Bunn, S.E. (2012). Assessing the seasonal dynamics of inundation, turbidity, and aquatic vegetation in the Australian wet-dry tropics using optical remote sensing. Ecohydrology, DOI: 10.1002/eco.1270.

Weiss, D.J., and Crabtree, R.L. (2011). Percent surface water estimation for MODIS BRDF 16-day image composites. Remote Sensing of Environment, 115, 2035-2046.

$\mathrm{Xu}, \mathrm{H}$. (2006). Modification of normalised difference water index (NDWI) to enhance open water features in remotely sensed imagery. International Journal of Remote Sensing, 27(14), 3025-3033. 